\title{
Prognostic impact of the number of viable circulating cells with high telomerase activity in gastric cancer patients: A prospective study
}

\author{
HIROAKI ITO $^{1}$, HARUHIRO INOUE ${ }^{1}$, SATOSHI KIMURA ${ }^{2}$, TOHRU OHMORI ${ }^{3}$, \\ FUMIHIRO ISHIKAWA ${ }^{4}$, KEIGO GOHDA ${ }^{5}$ and JUN SATO ${ }^{5}$ \\ ${ }^{1}$ Digestive Disease Center, Showa University Northern Yokohama Hospital; ${ }^{2}$ Department of Laboratory \\ Medicine and Central Clinical Laboratory, Showa University Northern Yokohama Hospital, Tsuzuki-ku, \\ Yokohama 224-8503; ${ }^{3}$ Institute of Molecular Oncology, Showa University School of Medicine; \\ ${ }^{4}$ Department of Cancer Cell Biology, Showa University School of Pharmacy, Shinagawa-ku, Tokyo 142-8555; \\ ${ }^{5}$ Central Research Laboratories, Sysmex Corporation, Nishi-ku, Kobe 651-2271, Japan
}

Received February 2, 2014; Accepted April 8, 2014

DOI: 10.3892/ijo.2014.2409

\begin{abstract}
The identification of circulating tumor cells (CTCs) in peripheral blood is a useful approach to estimate prognosis, monitor disease progression and measure treatment effects in several types of malignancies. We have previously used OBP-401, a telomerase-specific, replication-selective, oncolytic adenoviral agent carrying the green fluorescent protein (GFP) gene. GFP-positive cells $\left(\mathrm{GFP}^{+}\right.$cells) were counted under a fluorescence microscope. Our results showed that the number of at least $7.735 \mu \mathrm{m}$ in diameter $\mathrm{GFP}^{+}$cells $\left(\mathrm{L}-\mathrm{GFP}^{+}\right.$ cells) in the peripheral blood was a significant marker of prognosis in gastric cancer patients. However, tumor cells undergoing epithelial-mesenchymal transition (EMT) have been reported to be smaller in size than cells without EMT features; thus, CTCs undergoing EMT may escape detection with this technique. Therefore, in this study, we analyzed the relationship between patient outcome and the number of $\mathrm{GFP}^{+}$ cells of any size. We obtained peripheral blood samples from 65 patients with gastric cancer. After infection of OBP-401, $\mathrm{GFP}^{+}$cells were counted and measured. The relationship between the number of $\mathrm{GFP}^{+}$cells and surgical outcome was analyzed. The median follow-up period of the surviving patients was 36 months. A significant difference in overall survival was found between patients with $0-5$ and patients

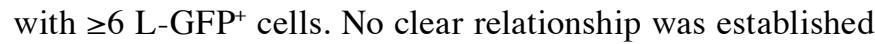
between the number of small-sized $\mathrm{GFP}^{+}$cells and patient

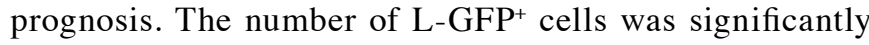
related to overall survival in patients with gastric cancer. The
\end{abstract}

Correspondence to: Dr Hiroaki Ito, Digestive Disease Center, Showa University Northern Yokohama Hospital, 35-1 Chigasakichuo, Tsuzuki-ku, Yokohama 224-8503, Japan

E-mail: h.ito@med.showa-u.ac.jp

Key words: circulating tumor cells, gastric cancer, telomerase detection of $\mathrm{L}-G F P^{+}$cells using OBP-401 may be a useful prognostic marker in gastric cancer.

\section{Introduction}

Distant metastasis is a strong prognostic factor in patients with solid tumors (1-3), and the presence of circulating tumor cells (CTCs) in peripheral blood indicates a systemic disease stage (4). The detection of CTCs in peripheral blood is useful for estimation of prognosis and monitoring of disease progression in breast, prostate, skin, colon and gastrointestinal malignancies. Although various methods have been developed to detect CTCs, the common techniques for the enrichment and detection of CTCs are density gradient separation $(5,6)$, direct enrichment by filtration (7), immunomagnetic separation (8), flow cytometry (9), real-time reverse transcriptase polymerase chain reaction (RT-PCR) $(10,11)$, and microchip technology (12). The CellSearch System (Veridex, LLC, Raritan, NJ, USA) (13) is based on immunomagnetic cell enrichment and is one of the most widely used automated techniques to enrich and detect CTCs (14-16). The advantage of immunomagnetic cell separation is that CTCs can be visualized with a fluorescence microscope. Cells detected with antibodies against epithelial markers [epithelial cell adhesion molecules (EpCAMs)] are determined to be CTCs. During epithelial-mesenchymal transition (EMT), an important developmental process in CTCs (17), epithelial surface markers are suggested to decrease (18). Thus, CTCs undergoing EMT may escape detection by systems using epithelial markers.

Increased telomerase activity is a common characteristic of malignant tumors, and telomerase plays important roles in carcinogenesis and disease progression $(19,20)$. Therefore, we have developed a novel detection system to enrich cells with high telomerase activity in peripheral blood samples from cancer patients. We used OBP-401 (TelomeScan, Oncolys BioPharma, Tokyo, Japan), which is a telomerase-specific, replication-selective modified viral agent in which the human telomerase reverse transcriptase (TERT) gene promoter is 
inserted into the E1 region, and the green fluorescent protein (GFP) gene is placed under the control of the cytomegalovirus promoter in the E3 region as a marker of viral replication (21). We obtained 7.5 -ml blood samples from 65 treatment-negative gastric cancer patients before surgery and 10 healthy volunteers (22). We detected viable CTCs in the blood samples after incubation with OBP-401. GFP-positive $\left(\mathrm{GFP}^{+}\right)$cells were detected in all blood samples. Since it has been reported that CTCs are larger than normal blood cells $(23,24)$, we counted $\mathrm{GFP}^{+}$cells having a diameter of at least $7.735 \mu \mathrm{m}\left(\mathrm{L}-\mathrm{GFP}^{+}\right.$ cells); this threshold was determined by receiver operating characteristic curve (ROC) analysis. As a result, there was a significant difference in overall survival between patients with $0-4$, and those with $\geq 5$ L-GFP ${ }^{+}$cells in both the stage I-IV disease and stage II-IV advanced disease groups. On the other hand, the number of $\mathrm{L}_{-} \mathrm{GFP}^{+}$cells showed no significant correlation to cancer stage. A pathological finding showed that the number of $\mathrm{GFP}^{+}$cells was only significantly related to venous invasion, although there was a trend of higher number of $\mathrm{L}-\mathrm{GFP}^{+}$cells with disease progression (22).

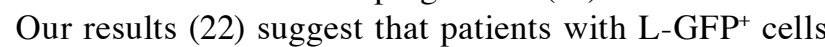
showed significant survival; however, other studies have shown that tumor cells undergoing EMT are smaller in size than cells without EMT features, because of changes in cell shape $(25,26)$. Thus, CTCs undergoing EMT possibly escape detection using our technique. Therefore, we analyzed the relationship between the number of $\mathrm{GFP}^{+}$cells of any size and patient outcome at a median-follow up of three years.

\section{Materials and methods}

Patients and healthy volunteers. This study is an interim analysis of our prospective preliminary study on CTCs from 65 patients with treatment-negative gastric adenocarcinoma, who underwent surgery at the Digestive Disease Center of the Showa University Northern Yokohama Hospital between April 2010 and May 2011, and from whom we extracted peripheral blood samples before treatment. The inclusion criteria were: i) histologically proven adenocarcinoma of the stomach by endoscopic biopsy; ii) clinical solitary tumor; iii) no prior endoscopic resection, chemotherapy, or radiotherapy; iv) ages, 20-80 years; v) Eastern Cooperative Oncology Group performance status (27) of 0 or 1; vi) sufficient organ function; and vii) written informed consent. The exclusion criteria were: i) synchronous or metachronous malignancy; ii) pregnant or breast-feeding women; iii) active or chronic viral hepatitis; iv) active bacterial or fungal infection; v) diabetes mellitus; vi) systemic administration of corticosteroids; and vii) unstable hypertension. The pathologic stage of the disease was determined according to the seventh edition American Joint Committee on Cancer (AJCC)/International Union Against Cancer (UICC) TNM classification system (28). The depth of the tumor invasion in four patients without gastrectomy and the regional lymph node status of seven patients without sufficient lymphadenectomy were surgically diagnosed.

All the patients were checked regularly every three months in our hospital after surgery. The patients also underwent endoscopy and computed tomography at least once a year, according to their disease stage and course. Healthy volunteers were also recruited to act as controls. All healthy volunteers were employees of Sysmex Corporation, which included seven men (mean age, 31.4 years; range, 24-39 years) and three women (mean age, 33.7 years; range, 26-48 years). All volunteers underwent medical check-ups upon employment and annually; check-ups included medical interviews, auscultation, chest radiography, and blood and urine analyses. In addition, individual interviews were done before sample collection; any volunteer who was currently receiving medical treatment, pregnant, or breast-feeding or who had donated blood within the past month was excluded.

The study was approved by the Institutional Review Board of the Showa University, Northern Yokohama Hospital (no. 0903-03). The study protocol was explained to the patients and volunteers before written informed consent was obtained. This study was registered with the University Hospital Medical Information Network in Japan (no. 000004026).

Virus. OBP-401, a telomerase-specific, replication-selective adenoviral agent in which the TERT promoter element drives the expression of the EIA and EIB genes and into which the GFP gene is integrated, was used. The sensitivity and specificity of the assay using OBP-401 have been reported previously by Kim et al (29). The test was repeated five times. In the sample containing one MDA-MB-468 (breast carcinoma) cell and 7.5-ml blood, the numbers of $\mathrm{GFP}^{+}$cells were one, one, one, two, and three; in the sample containing 20 MDA-MB-468 (breast carcinoma) cells, the numbers of $\mathrm{GFP}^{+}$cells were 15, $17,19,22$, and 24 . Viral samples were stored at $-80^{\circ} \mathrm{C}$.

Sample preparation and immunostaining. Details of sample preparation and assay have been described in our previous study (22). A 7.5-ml peripheral vein blood sample was obtained from each patient before surgery and from each volunteer. The samples were drawn into tubes containing citric acid, phosphoric acid, and dextrose and stored at $4^{\circ} \mathrm{C}$. The assay was started within $48 \mathrm{~h}$ of sample collection. The samples were centrifuged for $5 \mathrm{~min}$ at $540 \mathrm{xg}$, and the plasma phase was removed. The cells were then washed four times with phosphate-buffered saline (PBS) and twice with Roswell Park Memorial Institute medium. The samples were infected with $4 \times 10^{8}$ plaque-forming units (PFU) of OBP-401 virus by incubation in the medium for $24 \mathrm{~h}$ at $37^{\circ} \mathrm{C}$. Dead cells were stained with the red-fluorescent reactive dye L23102 (Life Technologies, Carlsbad, CA, USA), OBP-401 was inactivated, and cells were fixed with $2 \%$ paraformaldehyde for $20 \mathrm{~min}$ at room temperature. The samples were treated with a surfaceactive agent (Emalgen 2025G; Kao Chemicals, Tokyo, Japan) for $10 \mathrm{~min}$ at $40^{\circ} \mathrm{C}$ to degrade red blood cells. Phycoerythrinlabeled anti-human CD45 antibody (BioLegend, San Diego, CA, USA) was diluted 1:5, and Pacific Blue-labeled anti-human CD326 (EpCAM) antibody (BioLegend) was diluted 1:10 in PBS containing $2 \%$ fetal bovine serum. Cells were incubated with the diluted antibodies for $30 \mathrm{~min}$ at $25^{\circ} \mathrm{C}$. After being washed with PBS containing $2 \%$ fetal bovine serum, the cells were mounted on two glass slides for microscopic analysis.

Determination of GFP fluorescence intensity threshold. The threshold for GFP fluorescence intensity was determined as previously reported (22). Briefly, $\sim 30,000$ cultured cells were added into $7.5-\mathrm{ml}$ blood samples from healthy volunteers, 
which were mixed with various cancer cell lines: A549 (lung carcinoma), HepG2 (hepatocellular carcinoma), HEC-1 (endometrial carcinoma), KATO-III (gastric carcinoma), SBC-3 (small cell lung carcinoma), LNCaP (prostate adenocarcinoma), MDA-MB-MB468 (breast carcinoma), and OVCAR-3 (ovarian carcinoma); the cell lines were cultured according to the vendor's specifications. The blood samples were assayed using CTC detection assay, and the detectable cells were counted by fluorescence microscopy. More than 100 cells were analyzed in each sample. The GFP signal intensity threshold was determined to be $2.85 \times 10^{7}$ mean equivalent fluorochrome on the basis of the minimal GFP intensity level observed in the blood samples mixed with the cell lines. In addition, there was no significant difference of cell size between the cell before and after OBP-401 infection.

Determination of cell size threshold. In our previous study (22), various sizes of $\mathrm{GFP}^{+}$cells were observed in each sample, making it difficult to identify representative $\mathrm{GFP}^{+}$ cells for comparison between patients and healthy volunteers. Therefore, to establish a constant value, we used the optimum threshold derived from the ROC analysis based on cell size, that is, $7.735 \mu \mathrm{m}$, as the threshold to define GFP-positive CTCs. In this study, we categorized $\mathrm{GFP}^{+}$cells into two groups: smaller $\left(\mathrm{S}-\mathrm{GFP}^{+}\right.$cells) or larger $\left(\mathrm{L}-\mathrm{GFP}^{+}\right.$cells) than $7.735 \mu \mathrm{m}$ in diameter (Fig. 1).

Cell counting and analysis. All $\mathrm{GFP}^{+}$cells on the two slides were analyzed using a computer-controlled fluorescence microscope (IX71, Olympus, Tokyo, Japan); the observer was blinded to the sample detail. S-GFP ${ }^{+}$cells with fluorescent emissions $\geq 2.85 \times 10^{7}$ mean equivalent fluorochrome were counted as $\mathrm{GFP}^{+}$cells. $\mathrm{GFP}^{+}$cells included epithelial markerpositive and epithelial marker-negative cells because tumor cells undergoing EMT have been reported to be epithelial marker, such as EpCAM and cytokeratin, negative (18). $\mathrm{CD} 45^{+}$cells were excluded from the analysis.

Statistical analysis. All statistical analysis was performed using JMP Pro 10.0.0.2 (SAS Institute, Cary, NC, USA). Parametric comparisons were done using analysis of variance, and nonparametric comparisons were done using the Wilcoxon and Kruskal-Wallis tests. ROC curve analysis was performed to examine the relationship between patient outcome and the number of $\mathrm{GFP}^{+}$cells. The log-rank test was also used to calculate overall and relapse-free survival rates. Cox proportional hazards analysis was used to investigate risk factor for survival; $\mathrm{P} \leq 0.05$ was considered statistically significant.

\section{Results}

Participant characteristics. The clinicopathological characteristics of 65 patients (46 men and 19 women; mean age 60.7 years; range 33-76 years) are summarized in Table I. The median follow-up period of surviving patients was 36 months. Fifty-seven of the 65 patients underwent pathological curative surgery, and of these patients, nine experienced disease recurrence. Fourteen patients died. Twenty-nine patients had distal gastrectomy, 32 had total gastrectomy, and four had exploratory laparotomy. Twenty-eight of the 65 patients received
Table I. Patient characteristics and pathological findings.

\begin{tabular}{l} 
Variable No. of \\
\hline Gender \\
Male \\
Female
\end{tabular}

Age (years; mean, range)

$58.8(33-76)$

Gastrectomy

Distal 29

Total 32

None $\quad 4$

Curability

R0

57

$\mathrm{R} 1$

0

$\mathrm{R} 2$

8

TNM stage

I

40

II

6

III

10

IV

Depth of tumor invasion

T1

36

T2

T3

8

9

T4

12

Lymph node metastasis

No

39

N1

5

$\mathrm{N} 2$

6

15

N3

56

M0

9

Main histological type

Differentiated

25

Undifferentiated

Lymphatic invasion

LO

L1

LX

Venous invasion

V0

35

V1-2

26

VX

4

Postoperative chemotherapy

Yes (oral)

Yes (oral and infusion)

9

No

37

${ }^{a}$ Well-differentiated or moderately differentiated adenocarcinoma and papillary adenocarcinoma were categorized as differentiated type. Signet-ring cell carcinoma, poorly differentiated adenocarcinoma, and mucinous adenocarcinoma were categorized as undifferentiated type. 

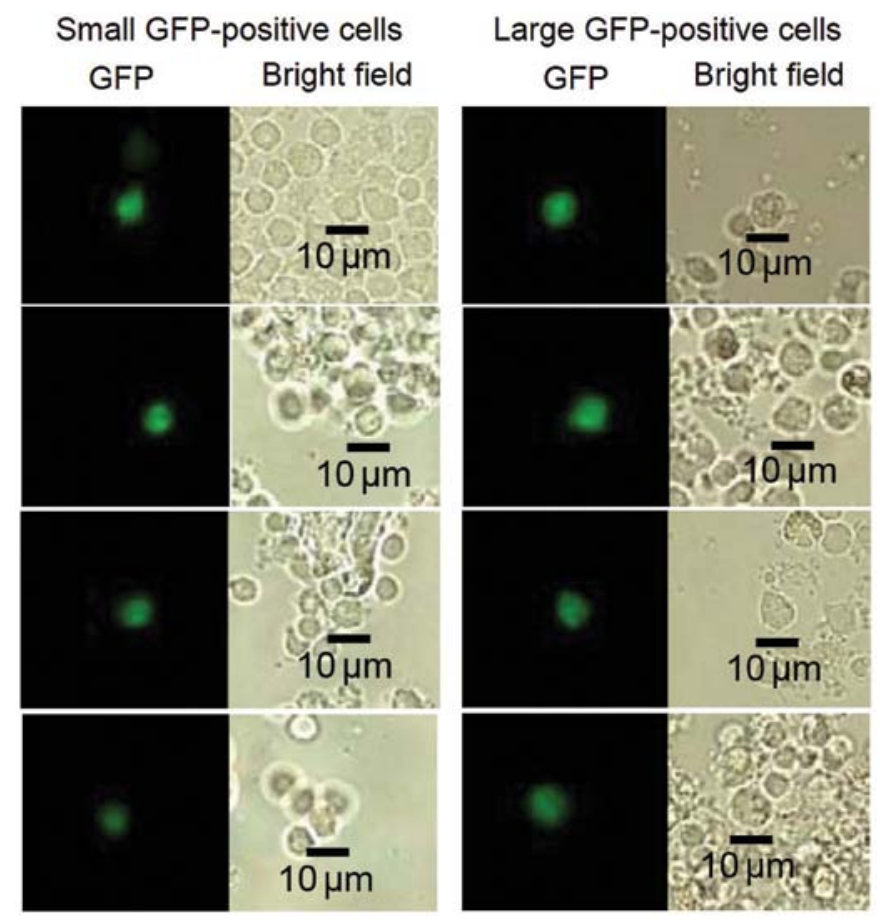

Figure 1. Examples of microscopic images. Representative images from gastric cancer samples of GFP-positive cells were counted using a computercontrolled fluorescence microscope by an examiner blinded to the sample status. Scale bar, $10 \mu \mathrm{m}$.

chemotherapy after surgery, 19 patients received oral chemotherapy (S-1), and 9 received oral chemotherapy combined with infusion (S-1/cisplatin and S-1/docetaxel).

Association of GFP-positive cells with pathological indices. Comparison of $\mathrm{GFP}^{+}$cells between healthy volunteers and patients are shown in Fig. 2. The numbers of $\mathrm{GFP}^{+}$cells (any size) and S-GFP cells in the samples from the health volunteers were significantly higher than the ones of the patients $(\mathrm{P}=0.038$ and 0.006$)$. There was no significant difference in

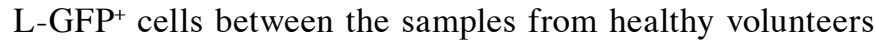
and the ones from the patients $(\mathrm{P}=0.760)$.

There was no significant relationship between the number of $\mathrm{GFP}^{+}$cells (any size, $\left.\mathrm{P}=0.329\right), \mathrm{S}_{-\mathrm{GFP}^{+}}$cells $(\mathrm{P}=0.424)$ and $\mathrm{L}-G F P^{+}$cells $(\mathrm{P}=0.213)$, and cancer stage (Fig. $\left.3 \mathrm{~A}\right)$. Although no statistical significance was observed, the number of $\mathrm{GFP}^{+}$ cells (any size) and S-GFP ${ }^{+}$cells tended to increase with the progression of the primary tumor (Fig. 3B). However, the number of $\mathrm{GFP}^{+}$cells in the samples from the node-positive patients was greater than that in the node-negative patients, there was no significant difference (Fig. 3C). Compared with the patients without distant metastases, those with distant metastases had relatively higher numbers of $\mathrm{GFP}^{+}$cells (Fig. 3D). The numbers of $\mathrm{GFP}^{+}$cells were similar in the samples from patients with and without lymphatic invasion (Fig. 3E). For venous invasion, the number of $\mathrm{L}_{-} \mathrm{GFP}^{+}$cells in the samples from the patients with invasion was significantly higher than that in patients without invasion ( $\mathrm{P}=0.031)$ (Fig. 3F).

Relationship between the patient outcome and the number and size of GFP-positive cells. The numbers of the detected $\mathrm{GFP}^{+}$cells in the peripheral blood samples are shown in Fig. 4.
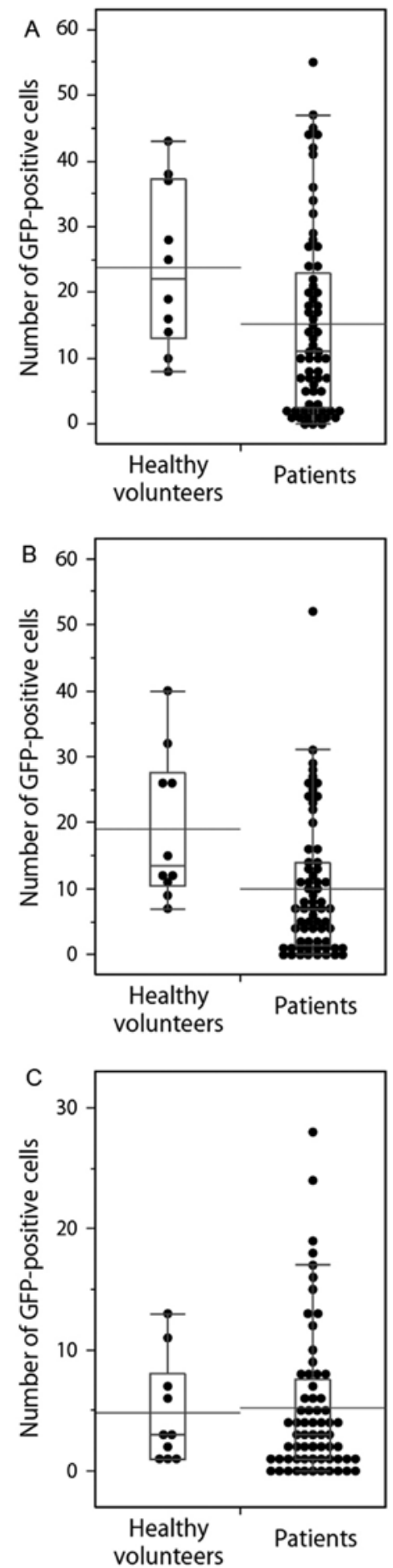

Figure 2. Number of GFP-positive $\left(\mathrm{GFP}^{+}\right)$cells. The dots indicate the numbers of $\mathrm{GFP}^{+}$cells in a 7.5-ml blood sample (A) any size, (B) $<7.735 \mu \mathrm{m}$ in diameter, $(\mathrm{C})>7.735 \mu \mathrm{m}$ in diameter. The bottom and top of the box represent the lower and upper quartiles, and the band across the box shows the median. The lower and upper bars at the ends of the whiskers show the lowest data point within 1.5 interquartile ranges of the lower quartile and the highest data point within 1.5 interquartile ranges of the upper quartile, respectively. The gray bars indicate mean value. The mean value of $\mathrm{GFP}^{+}$cells with any size, $>7.735 \mu \mathrm{m}$ and $<7.735 \mu \mathrm{m}$ were $23.8,4.8$ and 19.0 in the samples from healthy volunteers.

The mean value of $\mathrm{GFP}^{+}$cells with any size, $<7.735 \mu \mathrm{m}$ and $>7.735 \mu \mathrm{m}$ were $23.8,19.0$ and 4.8 in the samples from healthy volunteers, and 24, 19 and 5 were prescribed cutoff values of $\mathrm{GFP}^{+}$cells with any size, $<7.735 \mu \mathrm{m}$ and $>7.735 \mu \mathrm{m}$. The 

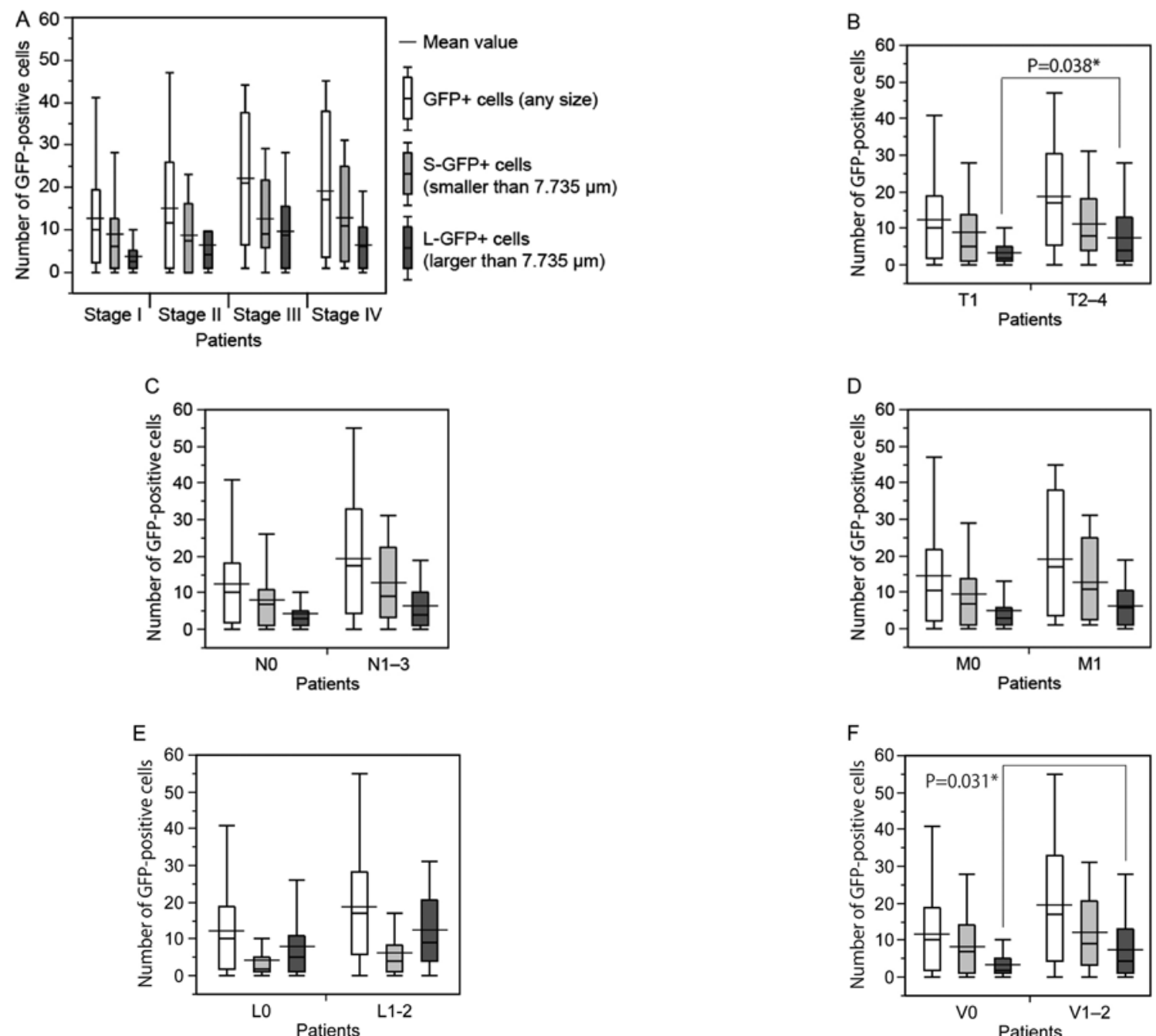

Figure 3. Relationship between number of GFP-positive $\left(\mathrm{GFP}^{+}\right)$cells in a 7.5-ml blood sample from gastric cancer patients and pathological findings in the patients. The bottom and top of the box represent the lower and upper quartiles, and the band across the box shows the median. The lower and upper bars at the ends of the whiskers show the lowest data point within 1.5 interquartile ranges of the lower quartile, and the highest data point within 1.5 interquartile ranges of the upper quartile, respectively. (A) TNM stage. (B) Depth of tumor invasion (T1-T4 indicate increasing depth). (C) Lymph node metastasis (N0, negative; N1-3, positive). (D) Distant metastasis (M0, negative; M1, positive). (E) Lymphatic invasion (L0, negative; L1, positive). (F) Venous invasion (V0, negative; V1-2, positive), ${ }^{*} \mathrm{P}<0.05$. Although depth of tumor invasion and venous invasion displayed statistically significant differences, there were some trends towards an increase in number of $\mathrm{GFP}^{+}$cells with increasing disease progression.
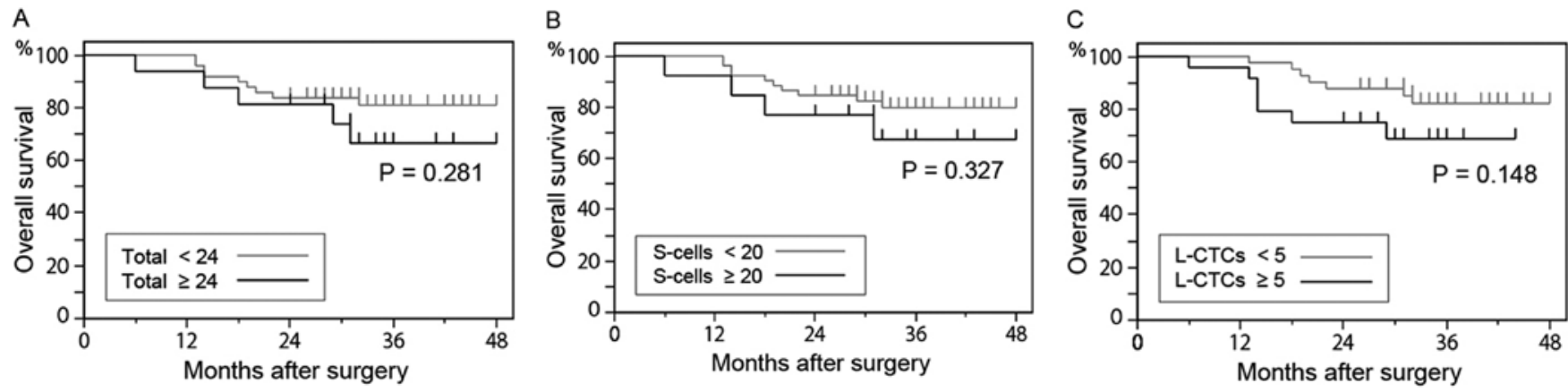

Figure 4. Overall survival using cutoff determined by mean number of GFP-positive (GFP ${ }^{+}$cells in samples from healthy volunteers. (A) GFP ${ }^{+}$cells (any size). (B) Small GFP ${ }^{+}$cells $(<7.735 \mu \mathrm{m})$. (C) Large $\mathrm{GFP}^{+}$cells $(>7.735 \mu \mathrm{m})$. Survival was compared according to the number of GFP cells using Kaplan-Meier analysis and the log-rank statistics. There was no significant difference between the overall survival rate and the number of GFP ${ }^{+}$cells.

overall survival rate of patients who had 24 or more $\mathrm{GFP}^{+}$ cells was lower than that of patients who had $<24 \mathrm{GFP}^{+}$ cells $(\mathrm{P}=0.281)$ (Fig. 4A); however, the difference was not significant. The overall survival rate of patients who had 20 or more GFP-positive S-GFP+ cells also tended to be lower than that of patients who had $<20$ GFP-positive S-GFP 

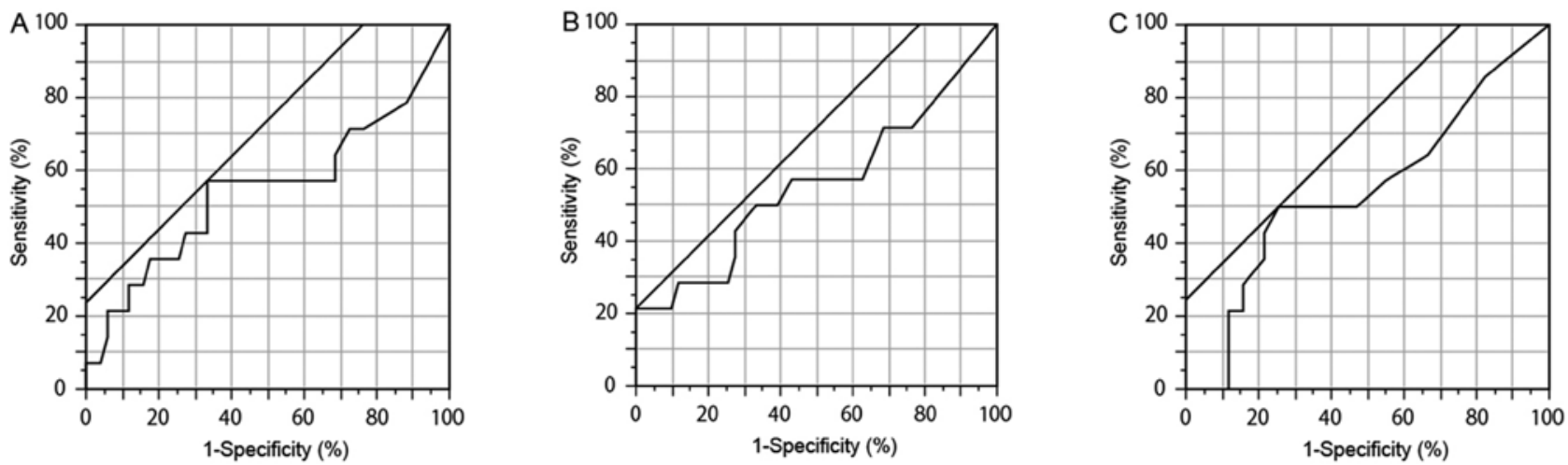

Figure 5. Comparison of GFP-positive $\left(\mathrm{GFP}^{+}\right)$cell number between surviving patients and deceased patients. To determine novel threshold, we compared the numbers of $\mathrm{GFP}^{+}$cells from surviving patients and deceased patients with gastric cancer by ROC analysis. (A) GFP ${ }^{+}$cells (any size). (B) Small $\mathrm{GFP}^{+}$cells $(<7.735 \mu \mathrm{m})$. (C) Large GFP large cells. The number of GFP ${ }^{+}$cells $(\mathrm{P}=0.241$, AUC 0.546 , cutoff 17 , sensitivity $55.6 \%$, and specificity $68.8 \%)$ and the number of large $\mathrm{GFP}^{+}$cells $(\mathrm{P}=0.770$, AUC 0.548 , cutoff 6 , sensitivity $44.4 \%$, and specificity $81.3 \%$ ) in the samples from the deceased patients were higher than those in the samples from the surviving patients. A prejudiced value was observed in small $\mathrm{GFP}^{+}$cells $(\mathrm{P}=0.159$, AUC 0.557 , cutoff 29 , sensitivity $22.2 \%$, and specificity $100 \%)$.
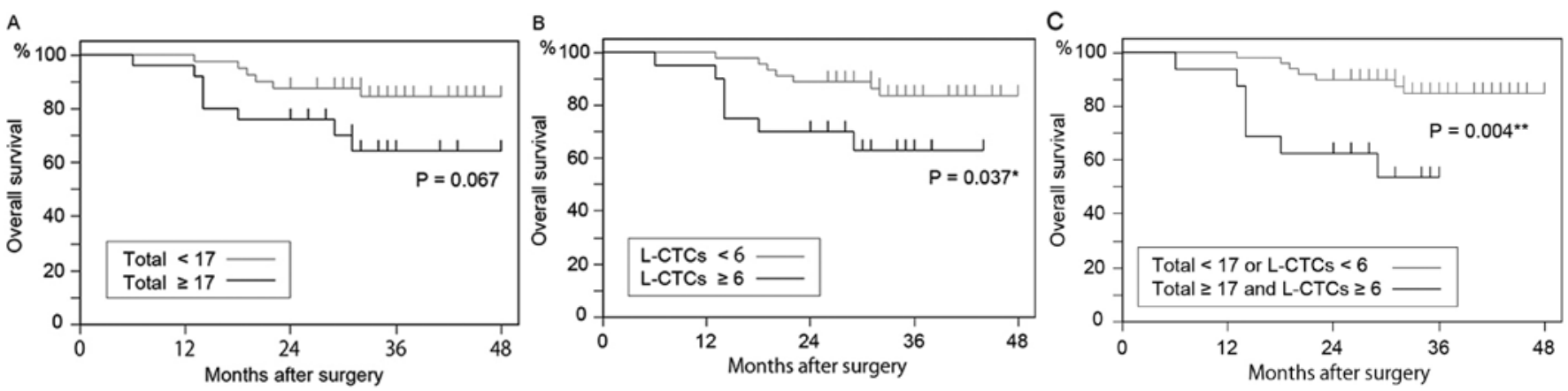

Figure 6. Overall survival using cutoff determined by ROC analysis. (A) GFP-positive (GFP') cells (any size). (B) Large GFP ${ }^{+}$cells $(>7.735 \mu \mathrm{m}$ ). (C) Combination of $\mathrm{GFP}^{+}$cells (any size) and large $\mathrm{GFP}^{+}$cells. Survival was compared according to the number of CTCs using Kaplan-Meier analysis and the log-rank statistics. ${ }^{* *} \mathrm{P}<0.01,{ }^{*} \mathrm{P}<0.05$.

cells $(\mathrm{P}=0.327)$ (Fig. 4B). Although there was no significant difference, the overall survival rate of patients who had 5 or more $\mathrm{L}-G F P^{+}$cells was lower than that of patients who had $<5 \mathrm{~L}-G F P^{+}$cells $(\mathrm{P}=0.148)$ (Fig. 4C).

We performed ROC analysis to determine another cutoff values. The ROC analysis showed that the numbers of $\mathrm{GFP}^{+}$cells $(\mathrm{P}=0.241$, AUC 0.546 , cutoff 17 , sensitivity $55.6 \%$, and specificity $68.8 \%)$ and $\mathrm{L}-\mathrm{GFP}^{+}$cells $(\mathrm{P}=0.770$, AUC 0.548 , cutoff 6 , sensitivity $44.4 \%$, and specificity $81.3 \%$ ) in the samples from the deceased patients were higher than those in the samples from the surviving patients (Fig. 5A and $\mathrm{B}$ ), although the difference was not significant. No particular tendency was observed in GFP-positive S-GFP cells $(\mathrm{P}=0.159$, AUC 0.557 , cutoff 29 , sensitivity $22.2 \%$, and specificity 100\%) (Fig. 5C). Based on these results, 17 and 6 were prescribed second cutoff values of $\mathrm{GFP}^{+}$cells with any size and $>7.735 \mu \mathrm{m}$. The overall survival rate of patients who had 17 or more $\mathrm{GFP}^{+}$cells was lower than that of patients who had $<17 \mathrm{GFP}^{+}$cells $(\mathrm{P}=0.067)$ (Fig. 6A); however, the difference was not significant. The overall survival rate of patients

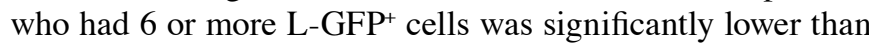
that of patients who had $<6 \mathrm{~L}-G F P^{+}$cells $(\mathrm{P}=0.037)$ (Fig. 6B). Moreover, the overall survival rate of patients who had both

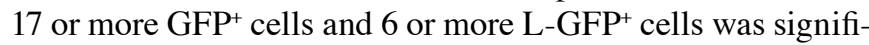

cantly lower than that of patients who had $<17 \mathrm{GFP}^{+}$cells or $<6$

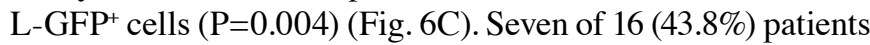
who had both 17 or more $\mathrm{GFP}^{+}$cells and 6 or more $\mathrm{L}_{-} \mathrm{GFP}^{+}$ cells, and 7 of 49 (14.3\%) patients who had $<17 \mathrm{GFP}^{+}$cells or $<6 \mathrm{~L}-G F P^{+}$cells deceased. In the 57 patients who underwent curative surgery, the relapse-free survival rate of the patients who had 17 or more $\mathrm{GFP}^{+}$cells was lower than that of patients who had $<17 \mathrm{GFP}^{+}$cells $(\mathrm{P}=0.130)$ (Fig. 7A); however, the difference was not significant. Although there was no significant difference, the relapse-free survival rate of patients who had 6 or more $\mathrm{L}-\mathrm{GFP}^{+}$cells was also lower than that of patients who had $<6 \mathrm{~L}-G F P^{+}$cells $(\mathrm{P}=0.124)$ (Fig. 7B). The relapse-free survival rate of the patients who had both 17 or more $\mathrm{GFP}^{+}$ cells and 6 or more $\mathrm{L}-G F P^{+}$cells was significantly lower than that of the patients who had $<17 \mathrm{GFP}^{+}$cells or $<6 \mathrm{~L}-\mathrm{GFP}^{+}$cells $(\mathrm{P}=0.015)$ (Fig. 7C).

\section{Discussion}

In this study, we analyzed the correlation between CTCs and prognosis in gastric cancer, which is the second leading cause of cancer-related death worldwide. The usefulness of the detection of CTCs in the diagnosis and estimation of prognosis has already been reported for breast $(14,30)$, prostate $(31)$, 


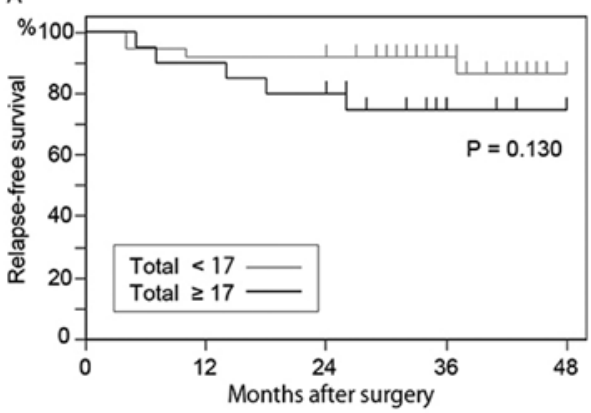

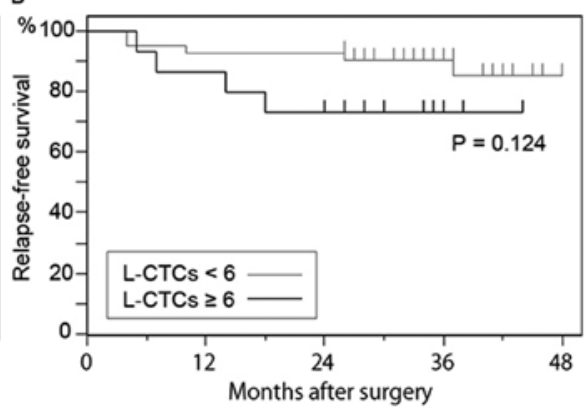

$c$

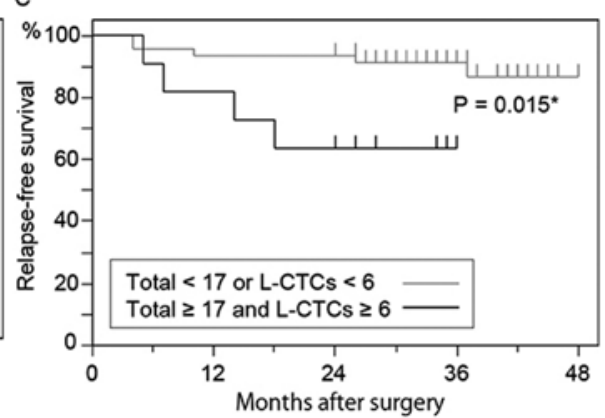

Figure 7. Relapse-free survival of 57 patients who underwent curative surgery using cutoff determined by ROC analysis. (A) GFP-positive (GFP ${ }^{+}$) cells (any size). (B) Large $\mathrm{GFP}^{+}$cells $(>7.735 \mu \mathrm{m})$. (C) Combination of $\mathrm{GFP}^{+}$cells (any size) and large $\mathrm{GFP}^{+}$cells. Survival was compared according to the number of CTCs using Kaplan-Meier analysis and the log-rank statistics. ${ }^{*} \mathrm{P}<0.05$.

lung (32), and digestive tract $(11,33)$ cancers. The results of the present study indicate that detection of CTCs may also be useful in the prognosis of gastric cancer.

This study showed two major findings. One was that the number of $\mathrm{L}-G F P^{+}$cells is significantly associated with patient prognosis. In our previous study (22), the prognosis of the patients who had 5 or more $\mathrm{GFP}^{+}$cells was significantly lower than that of the patients who had $<5 \mathrm{~L}-\mathrm{GFP}^{+}$cells. In this study, we obtained a similar result showing that the prognosis of patients who had 6 or more $\mathrm{L}_{-} \mathrm{GFP}^{+}$cells was significantly lower than that of patients who had $<6 \mathrm{~L}-G F P^{+}$ cells.

Further, we determined whether the number of $\mathrm{GFP}^{+}$cells of any diameter may be related to patient prognosis. Patients who had 17 or more $\mathrm{GFP}^{+}$cells showed lower survival rate than those who had $<17 \mathrm{GFP}^{+}$cells, although the difference was not significant. Since the combination of the number of total $\mathrm{GFP}^{+}$cells and $\mathrm{L}-\mathrm{GFP}^{+}$cells showed a significant correlation with patient prognosis whereas the number of only ${\mathrm{L}-\mathrm{GFP}^{+}}^{+}$ cells did not, we deemed the number of all $\mathrm{GFP}^{+}$cells to be related to patient prognosis. On the other hand, the relationship between the number of $\mathrm{S}-\mathrm{GFP}^{+}$cells and prognosis was unclear. Although there was a significant difference in the prognosis between patients who had 29 or more $\mathrm{S}-\mathrm{GFP}^{+}$cells $(n=2)$ and those who had $<29$ S-GFP ${ }^{+}$cells $(n=63)$, unequal numbers of patients were enrolled in the two groups. In our

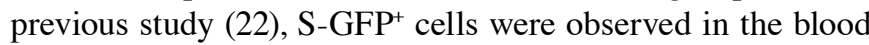
samples from healthy volunteers. Therefore, $\mathrm{S}-\mathrm{GFP}^{+}$cells may be detected as false-positive CTCs. There is possibility that OBP-401 infection caused increased telomerase activity in non-cancer cells.

One limitation of our study was that the metastatic potential of the detected CTCs was not determined. Our results

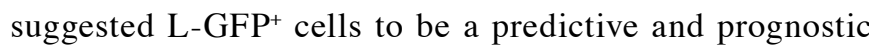
marker; however, further study is needed to determine the

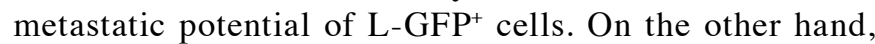

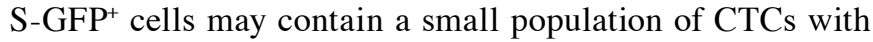
metastatic potential including tumor cells with EMT. It was suggested that the CTCs with EMT were included in both of

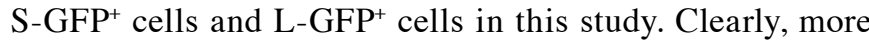
studies in a larger population of patients, and with different cancer types, are needed to clarify the clinical applicability of CTC detection. Thus, further studies should analyze the functions of viable CTCs after cell sorting, and identify
CTCs with metastatic potential using additional tools such as DNA ploidy analysis $(34,35)$. Furthermore, gene expression profiling of viable CTCs, dead cells, primary tumors, and metastatic tumors will also provide important insight into the mechanisms of cancer metastasis. Finally, the results of the present study indicate that CTCs are useful as predictors of disease progression in gastric cancer patients, but they do not constitute an independent prognostic factor.

The number of detected L-GFP ${ }^{+}$cells showed a significant relationship with prognosis in gastric cancer. However, the study used a short follow-up period and only a small number of participants. In addition, whether all $\mathrm{GFP}^{+}$cells have true metastatic potential was unclear. Further studies are warranted to confirm the findings of this study.

\section{Acknowledgements}

This study was supported in part by a Grant-in-Aid for Challenging Exploratory Research (23659308) from the Ministry of Education, Culture, Sports, Science, and Technology (MEXT). We are grateful to all the patients and volunteers who donated blood for this study. We would like to thank Professor Toshiyoshi Fujiwara (Okayama University Graduate School of Medicine, Okayama, Japan) for helpful comments and suggestions; Mr. Yasuo Urata (Oncolys BioPharma, Tokyo, Japan) for supplying the OBP-401; Dr Yukio Tsujino, Dr Toshiyuki Ozawa, and Dr Akinori Masago (Sysmex Corporation, Kobe, Japan) for their valuable support; and the clinical staff.

\section{References}

1. Kowalski LP: Lymph node metastasis as a prognostic factor in laryngeal cancer. Rev Paul Med 111: 42-45, 1993.

2. Nakane Y, Okamura S, Masuya Y, Okumura S, Akehira K and Hioki K: Incidence and prognosis of para-aortic lymph node metastasis in gastric cancer. Hepatogastroenterology 45: 1901-1906, 1998.

3. Arai Y, Kanamaru H, Yoshimura K, Okubo K, Kamoto T and Yoshida O: Incidence of lymph node metastasis and its impact on long-term prognosis in clinically localized prostate cancer. Int J Urol 5: 459-465, 1998.

4. Liotta LA, Kleinerman J and Saidel GM: Quantitative relationships of intravascular tumor cells, tumor vessels, and pulmonary metastases following tumor implantation. Cancer Res 34: 997-1004, 1974.

5. Hanahan D and Weinberg RA: The hallmarks of cancer. Cell 100: 57-70, 2000. 
6. Gertler R, Rosenberg R, Fuehrer K, Dahm M, Nekarda H and Siewert JR: Detection of circulating tumor cells in blood using an optimized density gradient centrifugation. Recent Results Cancer Res 162: 149-155, 2003.

7. Vona G, Sabile A, Louha M, et al: Isolation by size of epithelial tumor cells: a new method for the immunomorphological and molecular characterization of circulating tumor cells. Am J Pathol 156: 57-63, 2000.

8. Talasaz AH, Powell AA, Huber DE, et al: Isolating highly enriched populations of circulating epithelial cells and other rare cells from blood using a magnetic sweeper device. Proc Natl Acad Sci USA 106: 3970-3975, 2009.

9. He W, Wang H, Hartmann LC, Cheng JX and Low PS: In vivo quantitation of rare circulating tumor cells by multiphoton intravital flow cytometry. Proc Natl Acad Sci USA 104: 11760-11765, 2007.

10. Ito H, Kanda T, Nishimaki T, Sato H, Nakagawa $\mathrm{S}$ and Hatakeyama K: Detection and quantification of circulating tumor cells in patients with esophageal cancer by real-time polymerase chain reaction. J Exp Clin Cancer Res 23: 455-464, 2004.

11. Honma H, Kanda T, Ito $\mathrm{H}$, et al: Squamous cell carcinomaantigen messenger RNA level in peripheral blood predicts recurrence after resection in patients with esophageal squamous cell carcinoma. Surgery 139: 678-685, 2006.

12. Nagrath S, Sequist LV, Maheswaran S, et al: Isolation of rare circulating tumour cells in cancer patients by microchip technology. Nature 450: 1235-1239, 2007.

13. Cohen SJ, Punt CJ, Iannotti N, et al: Relationship of circulating tumor cells to tumor response, progression-free survival, and overall survival in patients with metastatic colorectal cancer. J Clin Oncol 26: 3213-3221, 2008

14. Riethdorf S, Fritsche H, Muller V, et al: Detection of circulating tumor cells in peripheral blood of patients with metastatic breast cancer: a validation study of the CellSearch system. Clin Cancer Res 13: 920-928, 2007.

15. Davis JW, Nakanishi H, Kumar VS, et al: Circulating tumor cells in peripheral blood samples from patients with increased serum prostate specific antigen: initial results in early prostate cancer. J Urol 179: 2187-2191, 2008.

16. Hou JM, Greystoke A, Lancashire L, et al: Evaluation of circulating tumor cells and serological cell death biomarkers in small cell lung cancer patients undergoing chemotherapy. Am J Pathol 175: 808-816, 2009.

17. Ksiazkiewicz M, Markiewicz A and Zaczek AJ: Epithelialmesenchymal transition: a hallmark in metastasis formation linking circulating tumor cells and cancer stem cells. Pathobiology 79: 195-208, 2012.

18. Gorges TM, Tinhofer I, Drosch M, Roese L, Zollner TM, Krahn T and von Ahsen O: Circulating tumour cells escape from EpCAM-based detection due to epithelial-to-mesenchymal transition. BMC Cancer 12: 178, 2012.

19. Kim NW, Piatyszek MA, Prowse KR, et al: Specific association of human telomerase activity with immortal cells and cancer. Science 266: 2011-2015, 1994

20. Blackburn EH: Telomere states and cell fates. Nature 408: 53-56, 2000.

21. Fujiwara T, Kagawa S, Kishimoto H, et al: Enhanced antitumor efficacy of telomerase-selective oncolytic adenoviral agent OBP-401 with docetaxel: preclinical evaluation of chemovirotherapy. Int J Cancer 119: 432-440, 2006.
22. Ito $\mathrm{H}$, Inoue $\mathrm{H}$, Sando $\mathrm{N}$, et al: Prognostic impact of detecting viable circulating tumour cells in gastric cancer patients using a telomerase-specific viral agent: a prospective study. BMC Cancer 12: 346, 2012.

23. Lin HK, Zheng S, Williams AJ, et al: Portable filter-based microdevice for detection and characterization of circulating tumor cells. Clin Cancer Res 16: 5011-5018, 2010.

24. Zheng S, Lin HK, Lu B, Williams A, Datar R, Cote RJ and Tai YC: 3D microfilter device for viable circulating tumor cell (CTC) enrichment from blood. Biomed Microdevices 13: 203-213, 2011

25. Thiery JP: Epithelial-mesenchymal transitions in tumour progression. Nat Rev Cancer 2: 442-454, 2002.

26. Brabletz T, Hlubek F, Spaderna S, Schmalhofer O, Hiendlmeyer E, Jung A and Kirchner T: Invasion and metastasis in colorectal cancer: epithelial-mesenchymal transition, mesenchymalepithelial transition, stem cells and beta-catenin. Cells Tissues Organs 179: 56-65, 2005.

27. Oken MM, Creech RH, Tormey DC, Horton J, Davis TE, McFadden ET and Carbone PP: Toxicity and response criteria of the Eastern Cooperative Oncology Group. Am J Clin Oncol 5: 649-655, 1982.

28. Sobin LH, Gospodarowicz MK and Wittekind C: International Union Against Cancer: TNM Classification of Malignant Tumours. 7th edition. Chichester, West Sussex, UK; Hoboken, NJ: Wiley-Blackwell; 2010.

29. Kim SJ, Masago A, Tamaki Y, et al: A novel approach using telomerase-specific replication-selective adenovirus for detection of circulating tumor cells in breast cancer patients. Breast Cancer Res Treat 128: 765-773, 2011.

30. Cristofanilli M, Budd GT, Ellis MJ, et al: Circulating tumor cells, disease progression, and survival in metastatic breast cancer. $\mathrm{N}$ Engl J Med 351: 781-791, 2004.

31. Moreno JG, Miller MC, Gross S, Allard WJ, Gomella LG and Terstappen LW: Circulating tumor cells predict survival in patients with metastatic prostate cancer. Urology 65: 713-718, 2005.

32. Krebs MG, Sloane R, Priest L, et al: Evaluation and prognostic significance of circulating tumor cells in patients with non-smallcell lung cancer. J Clin Oncol 29: 1556-1563, 2011.

33. Katsumata K, Sumi T, Mori Y, Hisada M, Tsuchida A and Aoki T: Detection and evaluation of epithelial cells in the blood of colon cancer patients using RT-PCR. Int J Clin Oncol 11: 385-389, 2006.

34. Bonsing BA, Beerman H, Kuipers-Dijkshoorn N, Fleuren GJ and Cornelisse CJ: High levels of DNA index heterogeneity in advanced breast carcinomas. Evidence for DNA ploidy differences between lymphatic and hematogenous metastases. Cancer 71: 382-391, 1993

35. Klijanienko J, el-Naggar AK, de Braud F, et al: Tumor vascularization, mitotic index, histopathologic grade, and DNA ploidy in the assessment of 114 head and neck squamous cell carcinomas. Cancer 75: 1649-1656, 1995. 